Universidade Tecnológica Federal do Paraná - UTFPR

Campus Ponta Grossa - Paraná - Brasil

ISSN: 1981-3686 / v. 01, n. 02: p. 93 - 103
Revista Brasileira de Tecnologia

Agroindustrial

\title{
CARACTERISTICAS DO MILHO DOCE (Zea mays L.) PARA INDUSTRIALIZAÇÃO
}

\section{CHARACTERISTICS OF SWEET CORN (Zea mays L.) FOR INDUSTRIALIZATION}

\author{
Angela Kwiatkowski ${ }^{1}$; Edmar Clemente ${ }^{2}$ \\ ${ }^{1}$ State University of Maringá - UEM - Maringá - Brasil angelak.k@gmail.com \\ ${ }^{2}$ State University of Maringá - UEM - Maringá - Brasil eclemente@uem.br
}

\section{Resumo}

No Brasil o milho doce é uma hortaliça voltada para o processamento industrial, sendo ainda pouco difundido para o consumo " in natura” pelo restrito número de cultivares adaptadas ao clima tropical. A principal diferença entre o milho doce e o milho convencional é a presença de alelos mutantes que bloqueiam a conversão de açúcares em amido, no endosperma, conferindo o caráter doce, tornando o milho doce enrugado e translúcido quando seco. As características exigidas pelo mercado consumidor de milho doce diferenciam-se das do milho verde comum. A indústria tem preferência por cultivares que possui maior teor de açúcar e menor teor de amido, além de maturação, tamanho e formato de espigas uniforme. A textura e a espessura do pericarpo do grão também são fatores de qualidade do milho verde. Esses fatores estão diretamente associados à aceitação do produto pelos consumidores. Visando estas definições este trabalho tem como objetivos apresentar as características do milho doce para industrialização.

Palavras-chave: milho doce; composição química; qualidade.

\section{Introdução}

O milho doce (Zea mays L.) é classificado como especial e destina-se exclusivamente ao consumo humano. É utilizado principalmente como milho verde, tanto “in natura” como para processamento pelas indústrias de produtos vegetais em conserva (PEREIRA FILHO; CRUZ, 2002; ARAGÃO, 2002; OLIVEIRA JUNIOR et al., 2006; BORIN, 2005).

Este cereal é muito popular nos Estados Unidos e no Canadá. Nesses países, o milho doce é tradicionalmente consumido “in natura” (BORDALLO et al., 2005). Atualmente, a área mundial cultivada é de 900 mil hectares. No Brasil cultivam-se 36 mil hectares, onde praticamente 100\% da produção é destinada ao processamento industrial (BARBIERI et al., 2005). A produção concentra-se 
nos estados do Rio Grande do Sul, São Paulo, Minas Gerais, Goiás, Distrito Federal e Pernambuco (PARENTONI et al., 1990). Na região Nordeste, este produto, principalmente na forma de espiga, possui muita importância econômica devido ao expressivo consumo regional e a utilização como matéria prima de muitos pratos da culinária local (PEDROTTI et al., 2003).

A exploração da cultura é realizada durante todo o ano utilizando-se irrigação e o escalonamento da produção, permitindo um fluxo constante do produto para a comercialização (TEIXEIRA et al., 2001). Este seguimento tem crescido nos últimos anos e a tendência é a manutenção deste crescimento, visando principalmente o mercado para exportação (BARBIERI et al., 2005). Assim, o Brasil, como um grande produtor de milho comum, apresenta grande potencial para a produção de milho doce. Entretanto, em virtude do pouco conhecimento por parte dos consumidores e da pequena disponibilidade de sementes, seu cultivo tem sido restrito (TEIXEIRA et al., 2001). Acredita-se que, em pouco tempo, o milho doce se tornará uma importante cultura hortícola no Brasil, podendo ser uma alternativa agronômica rentável (ARAUJO et al., 2006b).

No Brasil, com a expansão do mercado de milho doce para a indústria de enlatamento de milho verde e maior preocupação com sua qualidade (ARAGÃO et al., 2003), algumas empresas governamentais e privadas vêm desenvolvendo programas de melhoramento para produção de cultivares de milho doce adaptadas ao clima de cada região (SCAPIM et al., 1995), que apresentem endosperma com conversão reduzida de açúcar em amido (GAMA et al., 1983; FORNASIERI FILHO, 1992).

Visando essas definições este trabalho tem como objetivos apresentar as características de qualidade do milho doce para a industrialização.

\section{Milho doce}

O milho doce (Zea mays L. grupo saccharata) pertence à família das Poáceas ou Gramínea, tribu Maydeae, do gênero Zea. Originário da América, provavelmente da região onde se situa o México, foi domesticado em um período entre 7.000 - 10.000 anos atrás. O homem herdou cerca de 300 raças de milho, caracterizadas pelas mais diferentes adaptações, tanto para condições climáticas, como para usos do cereal. A botânica e a reprodução do milho doce são idênticas a do milho comum (ARAGÃO, 2002). A cultura do milho doce, normalmente é anual. A propagação é feita por sementes e o plantio é feito diretamente no campo (KUROZAWA, 2007).

A planta possui em média de 1,30 a 2,50 m de altura, caule ereto, cilíndrico, fibroso, separado em porções por gomos, e, geralmente, recoberto por uma parte da folha, denominada bainha. As folhas 
são de tamanho médio a grande, cor verde-escura a verde-clara, flexíveis e tem uma nervura central branca, lisa e bem visível. A planta produz flor masculina (flecha ou pendão) na sua parte mais alta, onde produz os grãos de pólen e a flor feminina (espiga) à meia altura. Cada fio (cabelo) que sai da espiga é responsável pela produção de um grão, depois de fecundada. O milho doce produz bem em épocas do ano com média a alta temperatura e boa disponibilidade de água no solo durante todo o ciclo da planta. A colheita de espigas é feita, quando os grãos estão em estado leitoso. Os grãos maduros e secos ficam totalmente enrugados, devido ao seu baixo teor de amido na sua composição (PAIVA et al., 1992; KUROZAWA, 2007).

A doçura do milho doce é um caráter recessivo e os genes mutantes mais conhecidos são o sugary (su), shrunken (sh) e britte (bt) (LEMOS et al., 2002; ARAUJO et al., 2006a). Vários alelos foram identificados e utilizados comercialmente. Todos são caracterizados por promoverem alterações na composição dos carboidratos no endosperma e diferenciam-se quanto à proporção de amido e açúcar no grão, e em relação à posição nos cromossomos em que estes alelos estão localizados (ARAÚJO, 2001; TRACY, 2001).

O milho doce é caracterizado por possuir pelo menos um dos oito genes mutantes que afetam a biossíntese de carboidratos no endosperma, sendo os principais: shrunken-2 (sh2), localizado no cromossomo 3; brittle (bt), no cromossomo 5; sugary enhancer (se), sugary (su) e Brittle-2 (bt2), todos no cromossomo 4. Existem, ainda, o dull (du), no cromossomo 10, waxy (wx), no cromossomo 9; e amilose extender (ae), no cromossomo 5. Tais genes podem atuar de forma simples ou em combinações duplas ou triplas. Entretanto, associadas a este gene, estão algumas características indesejáveis, como baixa produtividade e baixa resistência ao ataque de pragas e doenças por causa do maior teor de açúcares, quando comparado ao milho comum (TRACY, 1994, OLIVEIRA JUNIOR et al., 2006).

O termo “maior teor de açúcares” do milho doce inviabiliza o processamento de alguns pratos, como o cural e a pamonha, por causa do teor de amido (PEREIRA FILHO; CRUZ; GAMA, 2003).

\section{Industrialização do milho doce}

O milho doce apresenta uma diversificação de uso muito grande. Pode ser utilizado em conserva, congelado na forma de espigas ou grãos, desidratado, colhido antes da polinização e usado como "baby corn” ou minimilho e, ainda, após a colheita, a palhada da cultura a ser utilizada para ensilagem (PEDROTTI et al., 2003). Para os produtores de hortigranjeiros pode ser uma fonte de renda compensadora em virtude do alto preço unitário das espigas e do aproveitamento da parte vegetativa que pode ser usada como feno ou silagem de alta qualidade (STORCK et al., 1984). A colheita deve 
ser realizada quando as espigas estiverem com 70 a 80 \% de umidade e de preferência nas primeiras horas da manhã, quando a umidade do ar é alta e a temperatura é menor em relação ao dia. Quando os grãos apresentarem elevado teor de umidade terá queda no rendimento industrial, resultante do elevado número de espigas no estádio “cristal” ou "bolha d’água”, que somente é permitido em um total de 8 \% pela indústria de conserva (CRUZ; PEREIRA FILHO, 2002; PEREIRA FILHO; CRUZ, 2003).

A alta tecnologia que vem sendo empregada no cultivo do milho doce, assim como sua utilização pela indústria, requer cultivares que, além de produtivas, sejam uniformes quanto à maturação, tamanho e forma das espigas. As características requeridas para a industrialização do milho doce são a uniformidade na altura das plantas e espigas, características essas que podem ser conseguidas pelo emprego de híbridos simples; uniformidade no teor de umidade nos grãos, que auxilia na palatabilidade do produto e na manutenção do sabor; alta produção de grãos por espiga, e, a textura dos grãos deve ser uniforme e apresentar-se com pericarpo fino (TOSELLO, 1978). Espigas maiores (em torno de $20 \mathrm{~cm}$ de comprimento) e grãos longos têm a preferência pela indústria devido a maior eficiência das máquinas degranadoras para retirar grãos inteiros (PAIVA JÚNIOR, 1992; PEREIRA FILHO; CRUZ; GAMA, 2003). Em relação ao consumidor, as características mais exigidas são a coloração amarelo-alaranjada e o pericarpo fino, contribuindo para maior maciez do grão (TEIXEIRA et al., 2001).

Após a colheita, o milho doce passa por um processo de seleção, em que são descartadas as espigas que apresentem danos externos aparentes (brocas, machucaduras, podridões), e as demais são classificadas tomando por referência o tamanho de espiga. Uma etapa importante no manuseio póscolheita do milho doce é a remoção do calor de campo do produto. Quanto mais rápido realizar o resfriamento, maior será sua vida útil, pois após a colheita a perda da doçura no grão é rápida, devido à hidrólise de sacarose que no endosperma imaturo é metabolizada para amido pela enzima sacaroseglucosil-transferase. As técnicas empregadas para o resfriamento rápido de milho doce são o vácuo e o hidro-resfriamento, muito usadas nos Estados Unidos (TOSELLO, 1978; MORETTI; HENZ, 2003).

Para o armazenamento é necessário o uso de temperaturas próximas a $0{ }^{\circ} \mathrm{C}$, mas não menores que $-0,6{ }^{\circ} \mathrm{C}$, sob o risco de congelamento da espiga (MORETTI; HENZ, 2003). O milho doce pode

perder até $14 \%$ do seu teor de açúcares quando armazenado a $20{ }^{\circ} \mathrm{C}$ por um período de apenas três horas. Essa perda pode ser reduzida a $4 \%$ em 24 horas e de 7 a $8 \%$ em 72 horas a $0{ }^{\circ} \mathrm{C}$ (CHITARRA e CHITARRA, 2005).

\subsection{Qualidade do milho doce}


Novos conceitos de qualidade do milho verde têm surgido com as novas demandas e os resultados de pesquisas (PAES, 2006). A qualidade do milho doce pode ser avaliada pela sua composição química e propriedades físicas, como textura e a espessura do pericarpo. O milho doce é avaliado, em parte, pela concentração dos carboidratos: açúcares redutores (glucose e frutose), sacarose e polissacarídeos solúveis em água (TOSELLO, 1978). Condições ambientais como altas temperaturas e chuvas excessivas tem sido associadas à baixas concentrações de açúcares e à menor preferência pelos consumidores (MICHAEL; ANDREW, 1986). A composição química pode ser alterada através da manipulação genética. Somente nos últimos anos é que melhoristas têm dado atenção a este aspecto. O milho é o cereal que apresenta maior numero de produtos industrializados, devido ao alto teor de carboidratos, proteínas, lipídeos e vitaminas (ARAGÃO, 2002).

A textura também é um fator importante na determinação da qualidade. Pesquisadores do mundo todo têm estudado a influência da textura na aceitação dos alimentos. A avaliação das características de textura pode ser um parâmetro determinante de condições de processamento.

\subsubsection{Composição química}

A composição química dos alimentos varia em função das espécies e cultivares. Pesquisadores, visando a finalidade a que se destina a espécie, vêm realizando trabalhos para modificar o teor de determinadas substâncias nas sementes. Os carboidratos são os componentes mais importantes nos cereais, formando 83 \% da matéria seca total das sementes de milho. Entre os carboidratos mais importantes estão os açúcares e o amido. Os açúcares presentes são a glucose, frutose, galactose, sacarose entre outros (CARVALHO; NAKAGAWA, 2000). O milho doce comparado com o milho comum apresenta, respectivamente, 34,7 \% e 68,7 \% de amido, e em relação à composição desse amido tem-se 32,6 \% e $25 \%$ de amilose e 67,4 \% e 75 \% de amilopectina, respectivamente (ZÁRATE; VIEIRA, 2003; KUROZAWA, 2007).

Os lipídios são encontrados em toda a semente e são representados na forma de glicerídeos de ácidos graxos, sendo predominante os insaturados. Os mais comuns são o oléico, linoléico e linolênico. Dentre os saturados encontram-se o palmítico e o esteárico (CARVALHO; NAKAGAWA, 2000). O teor de lipídios do milho está em torno de 4 \% (PAES, 2006).

A proteína apresenta-se em menor proporção que os carboidratos e os lipídios. As proteínas mais abundantes são as glutelinas e as prolaminas (80 - 90 \%). Albuminas e globulinas encontram-se em menor proporção (20 \%). O milho doce comparado com o milho comum apresenta 38,8 \% e 0,0 \% 
de proteínas solúveis em água na matéria seca, respectivamente (CARVALHO; NAKAGAWA, 2000, PAES, 2006).

Os minerais estão presentes em um teor de 3 a 6 \%. Estão concentrados no gérmen (78 \%) e na camada de aleurona, a última camada do endosperma. O mineral encontrado em maior abundância no milho é o fósforo (0,3 ppm), presente na forma de fitatos de potássio e magnésio. Enxofre ocorre no grão na forma orgânica, em quantidades significantes, como parte dos aminoácidos sulfurados. Outros minerais estão também presentes no milho em quantidades menores, sendo os mais importantes: cloro, cálcio, sódio, iodo, ferro, zinco, manganês, cobre, selênio, cromo, cobalto e cádmio (PAES, 2006).

A tabela 1 apresenta a composição química e o valor energético do milho doce "in natura”, envasado e cozido. Pode-se observar que o milho doce "in natura” possui valores de calorias, glicídios, proteínas, lipídios, e minerais maiores que para o milho doce envasado ou cozido.

Tabela 1 - Composição química e valor energético do milho doce.

\begin{tabular}{cccccccc}
\hline $\begin{array}{c}\text { Milho Doce } \\
\mathbf{( 1 0 0 g )}\end{array}$ & Calorias & Glicídios & Proteínas & Lipídios & Ca & P & Fe \\
(cal) & $\mathbf{( g )}$ & $\mathbf{( g )}$ & $\mathbf{( g )}$ & $\mathbf{( m g )}$ & $\mathbf{( m g )}$ & $\mathbf{( m g )}$ \\
\hline "In natura” & 386,50 & 66,72 & 11,62 & 8,13 & 9,00 & 182,00 & 0,32 \\
Envasado & 97,9 & 20,20 & 2,7 & 0,70 & 5,00 & 52,00 & 0,23 \\
Cozido & 99,9 & 20,20 & 2,7 & 0,70 & 5,00 & 52,00 & 0,23 \\
\hline
\end{tabular}

Fonte: FRANCO, 2005.

\subsubsection{Textura do pericarpo}

A textura do pericarpo é um fator primário na determinação da qualidade do milho doce. Todos os cultivares de milho doce apresentam espessamento do pericarpo no decorrer da maturação, mas a taxa varia conforme o cultivar. Embora haja pouca informação a respeito da herança desse caráter, parece existir uma relação de dominância do pericarpo tenro sobre o de textura grosseira; portanto, é um fator hereditário e ao mesmo tempo fisiológico, uma vez que todas as variedades tornam-se mais espessas com o avanço da maturação. Os fatores que podem influenciar são o período de maturação do grão e a textura do tecido imediatamente inferior ao pericarpo, tornando as técnicas de avaliação bastante subjetivas (HUELSEN, 1954).

No Brasil utiliza-se muito o teste de mastigação para uma avaliação preliminar da textura do pericarpo. A avaliação desta característica é dada pelo paladar, sendo utilizada uma escala que varia de 1 a 3. Nota 1: pericarpo tenro (sem pegar bagaço no dente); nota 2: pericarpo intermediário; nota 3: 
pericarpo grosseiro (o bagaço fica retido no dente) (MACHADO, 1980; OLIVEIRA; SANTOS, 1983; FORNASIERI FILHO et al., 1988).

Para o milho doce enlatado podem ser realizadas avaliações de suculência e resistência ao cisalhamento que são índices utilizados na predição do grau de qualidade que o produto atingirá após o enlatamento, segundo os padrões do USDA (UNITED STATES DEPARTAMENT OF AGRICULTURE) (CAMPOS et al., 1989).

\subsubsection{Espessura do pericarpo}

A espessura do pericarpo afeta diretamente na maciez do grão. Quanto mais fina, melhor a qualidade do milho verde (SAWAZAKI et al., 1990, KUROZAWA, 2007). TRACY et al. (1978), analisando a espessura do pericarpo do milho, encontraram uma variação muito grande, de duas até vinte camadas de células, com valores de 25 a $200 \mu$ de espessura. O pericarpo tenro é altamente desejável no melhoramento da qualidade do milho doce, entretanto, a semente fica muito susceptível ao ataque de patógenos (HUELSEN, 1954; TRACY; JUVIK, 1989). A espessura do pericarpo é um caráter de herança quantitativa e pode ser alterada pela seleção (ITO; BREWBAKER, 1981). Não é um caráter afetado pelo ambiente, mas, a variação entre genótipos é extensa (HELM; ZUBER, 1969).

\section{Conclusões}

A crescente demanda junto a novos padrões de consumo, resultantes do comportamento de um mercado consumidor cada vez mais exigente quanto às características de qualidade, leva as indústrias de milho doce em conserva a atender este mercado. A pós-colheita do milho doce é um fator muito importante da manutenção de sua qualidade, pois este tipo de milho é altamente perecível, em virtude de sua elevada atividade metabólica. E assim, muitas empresas alimentícias, visando oferecer um milho verde em conserva ao consumidor, que satisfaça as exigências relacionadas ao paladar, estão trocando o milho verde obtido do milho comum pelo milho doce, incentivando os produtores com novas cultivares obtidas para o clima tropical.

\footnotetext{
Abstract

Although, in Brazil, sweet corn is a vegetable turned to the industrial processing, it is still little widespread for consumption 'in natura', due to the restricted number of cultivars thoroughly adapted to
} 
the tropical climate. The main difference, between the sweet corn and the conventional corn, is the presence of mutant alleles that block sugar conversion into starch in the endosperm. On the other hand, endosperm, which is responsible for the sweet flavor turns the sweet corn grain wrinkled and translucent when the vegetable is dry. The characteristic demands, made by the sweet corn current consuming market, differ from the ones demanded by the common green corn market. The sweet corn industry has shown great preference for cultivars that possess larger content of sugar and smaller content of starch. Besides that, industries have observed uniform maturation, size and format of ears. Texture and thickness of the grain pericarp are also observed and seen as factors responsible for showing the quality of green corn. Those factors are directly associated to the consumer's acceptance of the product. The main objective of the present paper is to present the characteristics of sweet corn for industrialization.

Key-words: Sweet corn; chemical composition; quality.

\section{Referências}

ARAGÃO, C.A. Avaliação de híbridos simples braquíticos de milho super doce (Zea mays L.) portadores do gene shrunken--2 $\left(\mathbf{s h}_{2} \mathbf{s h}_{2}\right)$ utilizando o esquema dialélico parcial. Botucatu, 2002, 101p. Tese (Doutorado). Faculdade de Ciências Agronômicas - Universidade Estadual Paulista "Júlio de Mesquita Filho”.

ARAGÃO, C.A.; DANTAS, B.F.; ALVES, E.; CATANEO, A.C.; CAVARIANI, C.; NAKAGAWA, J. Atividade amilolítica e qualidade fisiológica de sementes armazenadas de milho super doce tratadas com ácido giberélico. Revista Brasileira de Sementes, v.25, n.1, p.43-48, 2003.

ARAUJO, E.F.; CORRÊA, P.C.; SILVA, R.F. Comparação de modelos matemáticos para descrição das curvas de dessorção de sementes de milho-doce. Pesq. agropec. bras., Brasília, v.36, n.7, p.991-995, 2001.

ARAUJO, E.F.; ARAUJO, R.F.; SOFIATTI, V.; SILVA, R.F. Maturação de sementes de milho-doce - grupo super doce. Revista Brasileira de Sementes, v. 28, n. 2, p.69-76, 2006 a.

ARAUJO, E.F.; ARAUJO, R.F.; SOFIATTI, V.; SILVA, R.F. Qualidade fisiológica de sementes de milho-doce colhidas em diferentes épocas. Bragantia, Campinas, v.65, n.4, p. 687-692, 2006b.

BARBIERI, V.H. B.; LUZ, J.M.Q.; BRITO, C.H. de; DUARTE, J.M.; GOMES, L.S.; SANTANA, D.G. Produtividade e rendimento industrial de híbridos de milho doce em função de espaçamento e populações de plantas. Hortic. Bras., Brasilia, v.23, n.3, p. 826-830, 2005.

BORDALLO, P.N.; PEREIRA, M.G.; AMARAL JÚNIOR, A.T.; GABRIEL, A.P.C. Análise dialélica de genótipos de milho doce e comum para caracteres agronômicos e proteína total. Hort. Bras., Brasília, v.23, n.1, p.123-127, 2005.

BORIN, A. L. D. C. Extração, absorção e acúmulo de nutrientes no milho doce cultivado em condições de campo. Uberlândia, 2005. 97p. Tese (Mestrado). Universidade Federal de Viçosa.

CAMPOS, S.S.; GONÇALVES, J.R.; MORI, E.E.M.; GASPARETTO, C.A. Reologia e textura de alimentos. Campinas, Impr. Univ., 1989. 84p.

CARVALHO, N.M.; NAKAGAWA, J. Composição química de sementes. In: CARVALHO, N.M. e NAKAGAWA, J. Sementes: ciência, tecnologia e produção. 4.ed. Jaboticabal: Funep, 2000. cap.5, p.66-97.

CHITARRA, M.I.F.; CHITARRA, A.B. Perdas pós-colheita. In:

fisiologia e manuseio. 2.ed. Lavras: UFLA, 2005. cap. 3, p. 151-202.

Pós-colheita de frutas e hortaliças:

CRUZ, J.C.; PEREIRA FILHO, I.A. Manejo e tratos culturais para o cultivo do milho verde. Circular Técnica, n.16.

Embrapa Milho e Sorgo: Sete Lagoas, p.1-9, Jan., 2002. 
FORNASIERI FILHO, D.; CASTELLANE, P.D.; DECARO, S. Competição de cultivares de milho doce. Hort. Bras., v.6, p.20-22, 1988.

FORNASIERI FILHO, D. A cultura do milho. Jaboticabal: FUNEP, 1992. 273p.

FRANCO, G. Tabela 2 - Composição química dos alimentos e valor energético. In: Tabela de composição química dos alimentos. 9.ed. São Paulo: Atheneu, 2005. cap.2, p.107-152.

GAMA, E.E.G.; MORO, J.R.; MAGNAVACA, R.; VIANA, R.T.; NASPOLINI FILHO, V. Melhoramento do milho. In: Empresa Brasileira de Assistência Técnica e Extensão Rural. Brasília, EMBRATER, p. 23-38, 1983.

HELM, J.L.; ZUBER, M.S. Pericarp thickness of dent corn inbreds lines. Crop Sci., v.9, p.803-804, 1969.

HUELSEN, W.A. Sweet Corn. New York, Interscience Publishers, 1954. 409p.

ITO, G.M.; BREWBAKER, J.L. Genetic advance through mass selection for tenderness in sweet corn. J. Amer. Soc. Hort. Sci., v.106, p.496-449, 1981.

KUROZAWA, C. Glossário. Globo Rural, disponível em <http://globoruraltev.globo.com/GRural/ 0,27062,LPTO-4373-0L-M,00.html>, acesso em: 20/08/2007.

LEMOS, M. A.; GAMA, E. E. G.; MENEZES, D.; SANTOS, V. F.; TABOSA, J. N.; MORAIS, M. S. L. Emergência em campo de híbridos simples de milho superdoce de um cruzamento dialélico. Hortic. Bras., Brasília, v.20, n.2, p.158-162, 2002.

MACHADO, J.A. Melhoramento genético do milho doce (Zea mays L.). Piracicaba, ESALQ/USP, 1980. 78p. (Tese M.S.).

MICHAEL, T.E.; ANDREW, R.H. Sugar accumulation in shrunken-2 sweet corn kernels. Crop Sci., v.26, p.104-107, 1986.

MORETTI, C. L.; HENZ, G. P. Manuseio pós-colheita de milho doce. In: PEREIRA FILHO, I. A. (Ed.). O cultivo do milho-verde. Brasília: Embrapa, 2003. cap.12, p.195-204.

OLIVEIRA JUNIOR, L.F.G.; DELIZA, R.; BRESSAN-SMITH, R.; PEREIRA, M.G.; CHIQUIERE, T.B. Seleção de genótipos de milho mais promissores para o consumo in natura. Ciênc. Tecnol. Aliment., Campinas, v.26, n.1, p. 159-165, jan.-mar., 2006.

PAES, M.C.D. Aspectos físicos, químicos e tecnológicos do grão de milho. Circular Técnica, n.75. Embrapa Milho e Sorgo: Sete Lagoas, p.1-6, Dez., 2006.

PAIVA, E.; VASCONCELOS, M.J.V.; PARENTONI, S.N.; GAMA, E.E.G.; MAGNAVACA, R. Seleção de progênies de milho doce de alto valor nutritivo com auxílio de técnicas eletroforéticas. Pesq. agropec. bras., Brasília, v.27, p.1213-1218, 1992.

PAIVA JUNIOR, M.C. Desempenho de diferentes cultivares para milho verde em diferentes épocas e densidade de semeadura. 1990. 66 f. Dissertação, (Mestrado) - Universidade Federal de Lavras, Minas Gerais.

PARENTONI, S.N.; GAMA, E.E.G.; MAGNAVACA, R.; REIFSCHSNEIDER, F.J.B.; VILLAS BOAS, G.L. Milho doce. Informe Agropecuário, v.14, p.17-22, 1990.

PEDROTTI, A.; HOLANDA, F.S.R.; MANN, E.N.; AGUIAR NETTO, A.O.;BARRETO, M.C.V.; VIEGAS, P.R.A. Parâmetros de produção do milho-doce em sistemas de cultivo e sucessão de culturas no Tabuleiro Costeiro Sergipano. In: SEMINÁRIO DE PESQUISA FAP-SE, Sergipe. Anais... Sergipe: FAP, 2003.

PEREIRA FILHO, I.A.; CRUZ, J.C. Colheita, transporte e comercialização. In: PEREIRA FILHO, I.A. (Ed.). O cultivo do milho verde. Brasília: Embrapa, 2003. cap.11, p.183-194..

PEREIRA FILHO, I.A.; CRUZ, J.C. Cultivares de milho para o consumo verde. Circular Técnica, n.15. Embrapa Milho e Sorgo: Sete Lagoas, p.1-7, Jan., 2002. 
PEREIRA FILHO, I.A.; CRUZ, J.C.; GAMA, E.E.G. Cultivares para o consumo verde. In: PEREIRA FILHO, I.A. (Ed.). O cultivo do milho verde. Brasília: Embrapa, 2003. cap.1, p.17-30.

SAWAZAKI, E.; ISHIMURA, I.; ROSSETO, C.J.; MAEDA, J.A.; SÁES, L.A. Milho verde: Avaliação da resistência à lagarta da espiga, da espessura do pericarpo e outras características agronômicas. Bragantia, Campinas, v.49, p.241-251, 1990.

SCAPIM, C.A.; CRUZ, C.D.; ARAÚJO, J.M. Cruzamentos dialélicos entre sete cultivares de milho doce. Hortic. Bras., Brasília, v.13, n.1, p.19-21. 1995.

STORCK, L.; LOVATO, C.; COMASSETTO, V. Avaliação do rendimento e outras características agronômicas de cultivares de milho doce. R. Cent. Ci. Rur., v.14, p.153-160, 1984.

TEIXEIRA, F.F.; SOUZA, I.R.P.; GAMA, E.E.G.; PACHECO, C.A.P; PARENTONI, S.N.; SANTOS, M. X.; MEIRELLES, W. F. Avaliação da capacidade de combinação entre linhagens de milho doce. Ciênc. agrotec., Lavras, v.25, n.3, p.483-488, 2001.

TOSELLO, G.A. Milhos especiais e seu valor nutritivo. In: PATERNIANI, E. Melhoramento e produção do milho no Brasil. Campinas: Fundação Cargill, 1978. cap.8, p.326-329.

TRACY, W.F.; CHANDRAVADANA, P.; GALINAT, W.C. More on pericarp and aleurone thickness in maize and its relatives. Maize Genet. Coop. News Lett., v.52, p.60-62, 1978.

TRACY, W.F.; JUVIK, J.A. Pericarp thickness of shrunken-2 population of maize selected for improved field emergence. Crop Sci., v.29, p.72-74, 1989.

TRACY, W.F. Sweet Corn. In: Specialty Corns, CRC Press, p. 147-187, 1994.

TRACY, W.F. Sweet corn. In: HALLAUER, A.R. Specialty corn, Boca Raton. p.155-198, 2001.

ZÁRATE, N.A.H.; VIEIRA, M. do C. Produção do milho doce cv. Superdoce em sucessão ao plantio de diferentes cultivares de inhame e adição de cama-de-frango. Hortic. Bras. v.21, n.1, Brasília, p.05-09, 2003.

\section{Agradecimentos}

Ao CNPq pela concessão de bolsa à primeira autora.

\section{Inserir aqui dados completos de todos os autores:}

Nome completo: Angela Kwiatkowski.

Filiação institucional: Universidade Estadual de Maringá - UEM - Maringá - PR - Brasil.

Função ou cargo ocupado: Mestranda do Curso de Pós-graduação em Agronomia - UEM - Maringá PR - Brasil.

Endereço completo para correspondência: Av. Colombo, 5790, Zona 07 - CEP. 87020-900 - Maringá PR - Brasil.

Telefones para contato: (44) 8409-4078 / 35250649.

e-mail: angelak.k@gmail.com 
Nome completo: Edmar Clemente.

Filiação institucional: Universidade Estadual de - UEM - Maringá - PR - Brasil.

Departamento: Departamento de Química - DQI.

Função ou cargo ocupado: Professor Associado.

Endereço completo para correspondência: Av. Colombo, 5790, Zona 07 - CEP. 87020-900 - Maringá PR - Brasil.

Telefones para contato: (44) 3261-3659.

e-mail:eclemente@uem.br 